\title{
Surface-Enhanced Oxidation and Determination of Isothipendyl Hydrochloride at an Electrochemical Sensing Film Constructed by Multiwalled Carbon Nanotubes
}

\author{
S. N. Prashanth, Shankara S. Kalanur, Nagappa L. Teradal, and J. Seetharamappa \\ Department of Chemistry, Karnatak University, Dharwad 580 003, India \\ Correspondence should be addressed to J. Seetharamappa, j_seetharamappa@rediffmail.com
}

Received 20 May 2011; Revised 15 October 2011; Accepted 27 October 2011

Academic Editor: Benjamín R. Scharifker

Copyright ( $) 2012$ S. N. Prashanth et al. This is an open access article distributed under the Creative Commons Attribution License, which permits unrestricted use, distribution, and reproduction in any medium, provided the original work is properly cited.

\begin{abstract}
The electrochemical behavior of isothipendyl hydrochloride (IPH) was investigated at bare and multiwalled-carbon-nanotube modified glassy carbon electrode (MWCNT-GCE). IPH $(55 \mu \mathrm{M})$ showed two oxidation peaks in Britton-Robinson (BR) buffer of $\mathrm{pH}$ 7.0. The oxidation process of IPH was observed to be irreversible over the $\mathrm{pH}$ range of 2.5-9.0. The influence of $\mathrm{pH}$, scan rate, and concentration of the drug on anodic peak was studied. A differential pulse voltammetric method with good precision and accuracy was developed for the determination of IPH in pure and biological fluids. The peak current was found to be linearly dependent on the concentration of IPH in the range of $1.25-55 \mu \mathrm{M}$. The values of limit of detection and limit of quantification were noticed to be 0.284 and $0.949 \mu \mathrm{M}$, respectively.
\end{abstract}

\section{Introduction}

Since the discovery by Iijima [1], carbon nanotube (CNT) including single-walled carbon nanotube (SWCNT) and multiwalled carbon nanotube (MWCNT), has attracted much attention due to its unique structure and extraordinary properties [2]. CNT possesses subtle electronic properties, huge surface area, efficient catalytic activity, and strong adsorption ability, high chemical and thermal stability, high elasticity, high tensile strength, and in some instances metallic conductivity $[3,4]$. The modification of electrode surfaces with MWCNT for use in analytical sensing is well documented. It has demonstrated the ability to promote the electrontransfer reactions of electroactive biomolecules [5-7]. These excellent properties suggest that CNT is a fascinating electrode material, and now, it is widely used in electrochemistry and electroanalytical chemistry [8-10].

Isothipendyl hydrochloride (Figure 1) is a phenothiazine-related drug and has a broad range of clinical applications as antipruritic for local and generalized allergic reactions and radiation sickness [11]. It reduces vascular permeability and significantly reduces secretory activities. Large doses may cause drowsiness, nausea, and vomiting.

Several methods have been reported for the determination of IPH in forensic samples, pharmaceutical formulations and body fluids [12-15]. Because of its pharmacological importance and lack of reports on its electrochemical behavior and analysis by voltammetry, we thought of investigating the electrochemical behavior of IPH at bare glassy carbon electrode (GCE) and over multiwalled carbon-nanotube modified glassy carbon electrode (MWCNT-GCE) in detail. Further, we have developed a differential pulse voltammetric method for the determination of IPH in pure and biological samples.

\section{Experimental}

2.1. Apparatus. Electrochemical studies were carried out on a CHI-1103A electrochemical analyzer (CH Instruments Ltd. Co., USA, version 9.03). A conventional three-electrode system consisting of a GCE ( $3 \mathrm{~mm}$ diameter) or MWCNT-GCE 


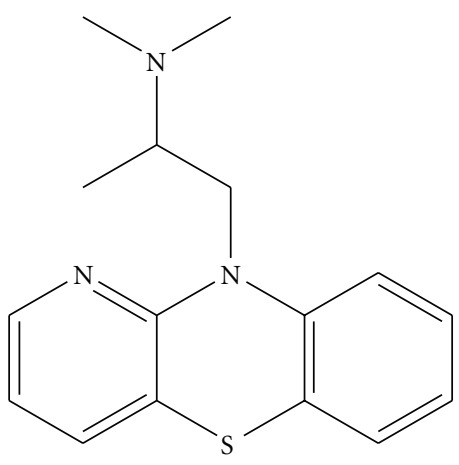

FIgURE 1: Structure of IPH.

as the working electrode, a platinum wire as a counter electrode, and an $\mathrm{Ag} / \mathrm{AgCl}(3 \mathrm{M} \mathrm{KCl})$ as reference electrode was employed. For reproducible results, improved sensitivity and resolution of voltammetric peaks, the working electrode was polished with 0.05 micron alumina powder on a polishing cloth. Then, it was thoroughly rinsed with milli-pore water. All the reported potentials are against $\mathrm{Ag} / \mathrm{AgCl}(3 \mathrm{M} \mathrm{KCl})$.

2.2. Reagents. MWCNTs were obtained from Sigma-Aldrich ( $>99 \%, 10-20 \mathrm{~nm}$ in diameter). Pure IPH was obtained from German Remedies Ltd. A stock solution of IPH $(2.5 \mathrm{mM})$ was prepared in millipore water and stored in a refrigerator at $4^{\circ} \mathrm{C}$. In the present study, BR buffer $(\mathrm{pH} 2.5-10.6)$ was used as supporting electrolyte. All the solutions were prepared in milli-pore water, and all other chemicals used were of analytical reagent grade.

2.3. Preparation of MWCNT-Modified GCE. MWCNTs were refluxed in concentrated nitric acid for about $5 \mathrm{~h}$, filtered, and washed with milli-pore water till the filtrate became neutral and finally dried [16]. The MWCNTs suspension was prepared by dispersing $2 \mathrm{mg}$ of MWCNTs in $10 \mathrm{~mL}$ acetonitrile using ultrasonic agitation to obtain a relatively stable suspension. Before modification, the GCE was carefully polished with $1.0,0.3$, and $0.05 \mu \mathrm{m} \alpha$-alumina on a smooth polishing cloth and then washed in methanol and water. The cleaned GCE was coated by casting $20 \mu \mathrm{L}$ of the black suspension of MWCNTs and dried in air. After modification, the electrode was rinsed with water for about $5 \mathrm{~min}$ to remove the loosely adsorbed nanotubes, if any.

2.4. Working Procedure. The MWCNT-GCE was first activated in BR buffer of $\mathrm{pH} 7.0$ by cyclic voltammetric sweeps between 0 and $1.4 \mathrm{~V}$ till stable cyclic voltammograms were obtained. The modified electrode was then transferred into $10 \mathrm{~mL} \mathrm{BR}$ buffer (pH 7.0.) containing IPH $(55 \mu \mathrm{M})$, and an accumulation time of $240 \mathrm{~s}$ was given. After this accumulation time, the electrode was used to record the cyclic voltammogram/differential pulse voltammogram.

Working solutions were prepared by diluting the stock solution as required with $\mathrm{BR}$ buffer $(0.04 \mathrm{M})$ of required $\mathrm{pH}$. For DPV, the following parameters were maintained: sweep rate $20 \mathrm{mV} \mathrm{s}^{-1}$, pulse amplitude $50 \mathrm{mV}$, pulse width $30 \mathrm{~ms}$, and pulse period $500 \mathrm{~ms}$. For analytical applications, oxidation peak a1 was selected. All electrochemical experiments were carried out at $25^{\circ} \mathrm{C}$. After every measurement, new MWCNT-GCE was prepared.

2.5. Determination of IPH in Human Urine and Plasma Samples. Spiked urine samples were obtained by treating $0.9 \mathrm{~mL}$ aliquots of urine with $100 \mu \mathrm{L} \mathrm{IPH}$ standard solution $(2.5 \mathrm{mM})$ to obtain $250 \mu \mathrm{M}$ IPH. A suitable aliquot of spiked urine was diluted with BR buffer, without any pretreatment, to prepare appropriate sample solution, and differential pulse voltammogram was recorded under optimized conditions.

Spiked serum samples were prepared by following the procedure reported earlier [17]. Serum samples, obtained from healthy individuals (after having obtained their written consent), were stored frozen until assay. For the determination of IPH in plasma, $500 \mu \mathrm{L}$ of IPH $(2.5 \mathrm{mM})$ was added to $500 \mu \mathrm{L}$ of untreated plasma. The mixture was vortexed for $30 \mathrm{~s}$. In order to precipitate the plasma proteins, the plasma samples were treated with $250 \mu \mathrm{L}$ perchloric acid (15\%). After that, the mixture was vortexed for further $30 \mathrm{~s}$ and then centrifuged at $5000 \mathrm{rpm}$ for $5 \mathrm{~min}$. An appropriate volume of supernatant liquor was transferred in the voltammetric cell containing BR buffer of $\mathrm{pH} 7.0$, and voltammograms were recorded. The voltammogram of sample without IPH did not show any signal that can interfere with the direct determination. The content of the drug in plasma was determined referring to the calibration graph or regression equation.

\section{Results and Discussion}

3.1. Cyclic Voltammogram of IPH at MWCNT-GCE. The cyclic voltammograms of $55 \mu \mathrm{M}$ IPH at bare GCE and MWCNT-GCE in BR buffer of pH 7.0 along with that of blank are shown in Figure 2. IPH showed two oxidation peaks at $0.721 \mathrm{~V}(\mathrm{a} 1)$ and $0.958 \mathrm{~V}(\mathrm{a} 2)$ at bare GCE (Figure 2 ). No reduction peak was observed in the reverse scan suggesting that the electrochemical oxidation of IPH was an irreversible process. At MWCNT-GCE, these oxidation peaks appeared at $0.696 \mathrm{~V}$ and $0.912 \mathrm{~V}$, respectively, with a considerable enhancement in the peak current. Thus, the negative shifts in peak potentials were observed to be $25 \mathrm{mV}$ and $46 \mathrm{mV}$ for peak a1 and a2, respectively, suggesting that MWCNT exhibited catalytic effect towards electrooxidation of IPH $[8,18]$.

Successive cyclic voltammograms were recorded to check the adsorption of the oxidation product of IPH on MWCNTGCE. The oxidation peak currents of IPH were found to be decreased during the successive scans and finally remained unchanged. This was attributed to the adsorption of oxidative product of IPH on the modified electrode surface.

3.2. Influence of Amount of MWCNT Suspension. The amount of MWCNT on GCE may influence the electrooxidation of IPH. With increase in the volume of MWCNT suspension from 0 to $20 \mu \mathrm{L}$, the oxidation peak current of IPH was observed to be increased remarkably (Figure not shown). The oxidation peak currents considerably increased 


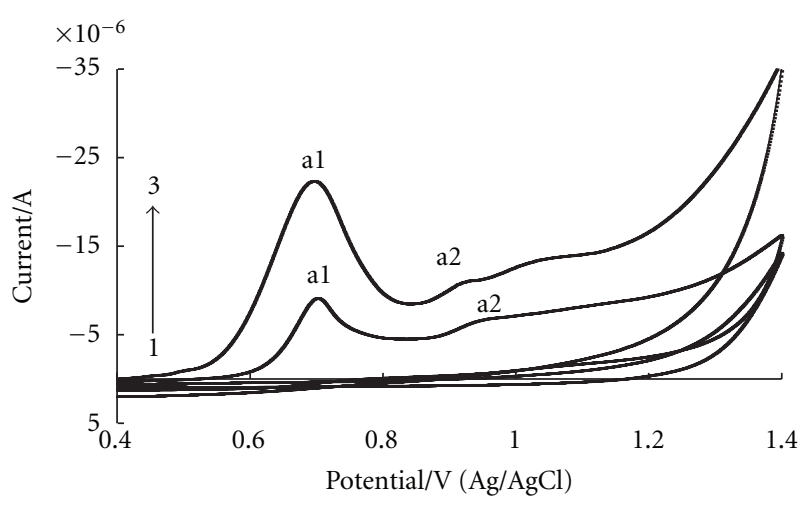

FIGURE 2: Voltammograms of blank buffer (1); $55 \mu \mathrm{M}$ IPH on bare GCE (2) and on MWCNT-GCE (3) in BR buffer of pH 7.0 at a scan rate of $50 \mathrm{mV} \mathrm{s}^{-1}$.

as the surface concentration of IPH at MWCNT-GCE increased. With further increase in the volume, the oxidation peak current remained almost constant. Considering the peak current as well as the time needed for evaporation of acetonitrile, $20 \mu \mathrm{L}$ of MWCNT suspension was used to modify the GCE surface.

3.3. Effect of Accumulation Time. Since the oxidation current is strongly dependent on the accumulation time, we have examined the influence of accumulation time on oxidation peak currents of IPH at the MWCNT-GCE. Accumulation of drug on the electrode surface was done under open circuit potential for different time intervals, and then cyclic voltammograms were recorded at a scan rate of $50 \mathrm{mV} \mathrm{s}^{-1}$. While maintaining the accumulation time of 0 to $240 \mathrm{~s}$, the oxidation peak currents increased remarkably (figure not shown). However, the oxidation peak currents decreased slightly with further increase in the accumulation time suggesting that the amount of IPH tends to a limiting value at the MWCNT film. Considering the sensitivity and working efficiency, an accumulation time of $240 \mathrm{~s}$ was maintained throughout.

3.4. Effect of $p H$. The electrochemical behavior of IPH in BR buffer of different $\mathrm{pH}$ values was studied. At $\mathrm{pH} 3.5$, the voltammogram of IPH was almost similar to that of promethazine (PMZ) owing to the close similarity in structure [19]. IPH is different from PMZ only in one benzene ring, which is replaced by pyridine ring in IPH. Two oxidation waves were seen on the initial scan, and no reduction peak was observed. Like in the case of another phenothiazine derivative, ethopropazine, the peak potential of al (of IPH) was $\mathrm{pH}$ dependent indicating the involvement of proton in the oxidation process [20]. With increase in $\mathrm{pH}$ from 2.5 to 7.0 , the oxidation peak currents of a 1 and a 2 gradually increased at MWCNT-GCE (Figure 3). Furthermore, increasing pH to 9.0, the oxidation peak currents of al gradually decreased with broader and ill-defined peaks. Apparently, the oxidation signals of IPH seemed to be sensitive in the buffer of $\mathrm{pH}$ 7.0.

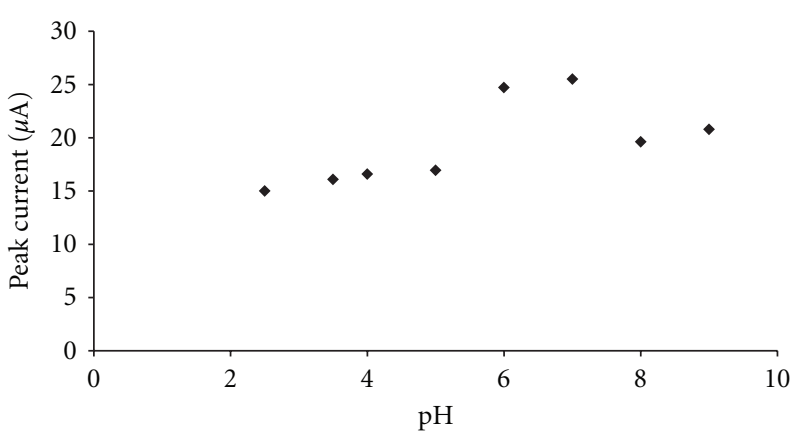

FIGURE 3: Plot of $I_{p a}$ versus $\mathrm{pH}$ for the electrooxidation of IPH on MWCNT-GCE in BR buffer at a scan rate of $50 \mathrm{mV} \mathrm{s}^{-1}$.

We have also investigated the effect of $\mathrm{pH}$ on the oxidation peak potential. With an increase in $\mathrm{pH}$ from 2.5 to 7.0 , the oxidation peak potential gradually shifted to negative potential suggesting that the protons were involved in the oxidation of IPH. The plot of peak potential of al versus $\mathrm{pH}$ showed a linear segment at $\mathrm{pH}$ 8.0. This intersection point of the curve was found to be close to the pKa value of IPH (8.6) [21]. This could be attributed to changes in protonation of acid-base properties of the molecule. The slope was found to be $29.6 \mathrm{mV} / \mathrm{pH}$, which is close to the reported value for PMZ $[22,23]$ and the theoretical value for a two-electron and oneproton transfer reaction. Thus, it could be concluded that the electrode reaction mechanisms of IPH and PMZ are identical at least over the $\mathrm{pH}$ range of 2.5-7.0.

3.5. Effect of Scan Rate. Useful information on electrochemical mechanism can be acquired from the relationship between peak current and scan rate. Therefore, the electrochemical behavior of IPH in BR buffer of pH 7.0 at different scan rates was studied and the results are shown in Figure 4.

The peak current was observed to be proportional to the scan rate indicating that the electrode process was adsorption controlled [24]. A linear relationship was observed between $\log I_{p a}$ and $\log v$ as per (1) shown below:

$$
\log I_{p a}(\mu A)=0.8255 \log v-3.5906 .
$$

The slope of 0.83 (obtained from the plot of $\log I_{p a}$ versus $\log v$ ) was noticed to be close to the theoretical value of 1.0 for an adsorption-controlled process $[25,26]$. The $E_{p a}$ of the oxidation peak was also noticed to be dependent on the scan rate. Further, the peak potential was shifted to more positive values with increase in the scan rates. Linear relationship was observed between $E_{p a}$ and scan rate indicating the irreversibility of the oxidation process with a correlation coefficient of 0.9883 according to (2) shown below:

$$
E_{p a}(V)=0.0011 \nu+0.6517 \text {. }
$$

\section{Analytical Applications}

4.1. Curve of Calibration. Differential pulse voltammetry was used for the determination of IPH because of its higher sensitivity compared to cyclic voltammetry. Sharper and 


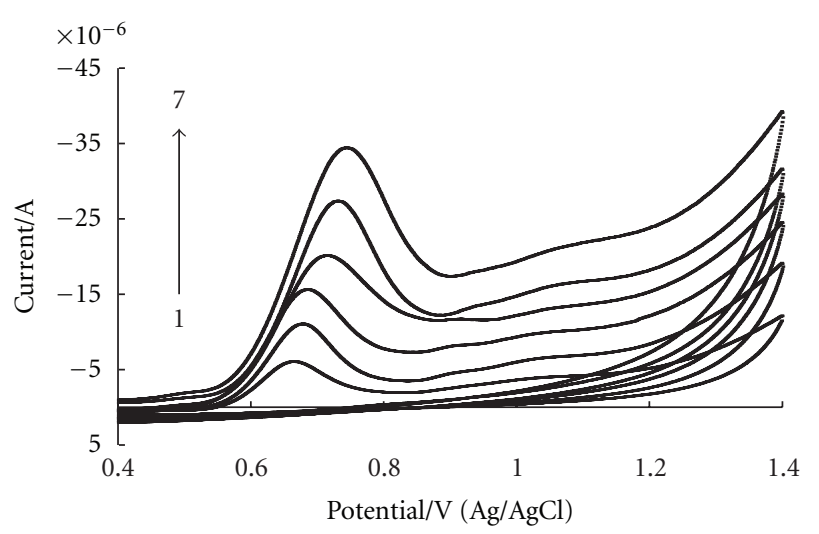

Figure 4: Voltammograms of $55 \mu \mathrm{M}$ IPH in Britton-Robinson buffer of pH 7.0 on MWCNT-GCE at different scan rates: (1) 10, (2) 20, (3) 30, (4) 40, (5) 60, (6) 80, and (7) $100 \mathrm{mV} \mathrm{s}^{-1}$.

TABLE 1: Characteristics of calibration plot of IPH.

\begin{tabular}{lc}
\hline & DPV \\
\hline Linearity range $[\mu \mathrm{M}]$ & $1.25-55$ \\
LOD $[\mu \mathrm{M}]$ & 0.28 \\
LOQ $[\mu \mathrm{M}]$ & 0.94 \\
Interday assay RSD [\%] & 1.41 \\
Intraday assay RSD $[\%]$ & 1.21 \\
\hline
\end{tabular}

well-resolved curves were obtained in BR buffer of $\mathrm{pH}$ 7.0. Under the optimized conditions (sweep rate $20 \mathrm{mV} \mathrm{s}^{-1}$, pulse amplitude $50 \mathrm{mV}$, pulse width $30 \mathrm{~ms}$, pulse period $500 \mathrm{~ms}$ ), a linear relation between the peak current and concentration of drug was observed in the range of 1.25-55 $\mu \mathrm{M}$ IPH (Figure 6). Beyond the IPH concentration of $55 \mu \mathrm{M}$, the linearity was lost. The differential pulse voltammograms of different concentrations of IPH are shown in Figure 5.

The plot of $I_{p a}$ versus the concentration of IPH showed linearity over the concentration range of $1.25-55 \mu \mathrm{M} \mathrm{IPH}$ with the correlation coefficient of 0.9931 . The corresponding linear relation expressing the dependence of $I_{p a}$ on concentration is shown below:

$$
I_{p a}(\mu A)=0.1053 C+3.1423,
$$

where $C$ is in $\mu \mathrm{M} \mathrm{L}^{-1}$. Characteristics of the calibration graph are recorded in Table 1.

The limit of detection (LOD) and limit of quantification (LOQ) were calculated based on the peak current using (4) and (5) $[27,28]$ :

$$
\begin{aligned}
\mathrm{LOD} & =3 \frac{s}{\mathrm{~m}}, \\
\mathrm{LOQ} & =10 \frac{\mathrm{s}}{\mathrm{m}},
\end{aligned}
$$

where $s$ is the standard deviation of the intercept $(n=5)$ of calibration plot and $m$ is the slope of the calibration curve. The LOD and LOQ values were found to be $0.28 \mu \mathrm{M}$ and $0.94 \mu \mathrm{M}$, respectively. The interday reproducibility of the

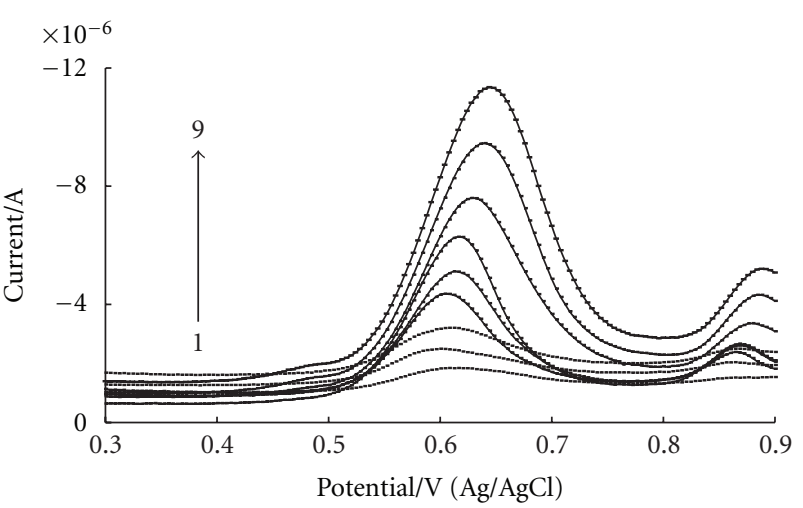

FIGURE 5: Differential pulse voltammograms of IPH at different concentrations: (1) 1.25 , (2) 2.5, (3) 5, (4) 10, (5) 18.8, (6) 25, (7) 35, (8) 45 , and (9) $55 \mu \mathrm{M}$.

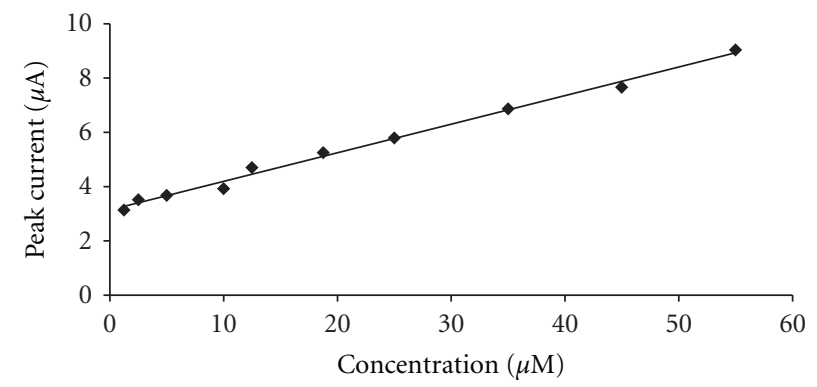

FIGURE 6: Relation between $I_{p a}$ and concentration of IPH on MWCNT-GCE at a scan rate of $50 \mathrm{mV} \mathrm{s}^{-1}$.

method was examined by recording voltammograms of 5 replicates of $5 \mu \mathrm{M}, 20 \mu \mathrm{M}$ and $50 \mu \mathrm{M}$ IPH. These yielded the RSD values of $1.28,1.42$, and $1.53 \%$, respectively. Further, the RSD values for intraday assay reproducibility at $5 \mu \mathrm{M}, 20 \mu \mathrm{M}$, and $50 \mu \mathrm{M}$ solutions $(n=5)$ were found to be respectively, $1.12,1.36$, and $1.15 \%$. The corresponding results are shown in Table 1. Low values of both LOD and LOQ confirmed the sensitivity of the proposed method. Further, the low values of RSD revealed the good precision of the proposed method for the assay of IPH.

4.2. Effects of Interferents. The selectivity of the proposed method was examined by studying the effects of interferents, namely, glucose, sucrose, starch, acacia powder, ascorbic acid, and talc. For this, we have recorded differential pulse voltammograms of $2.5 \mu \mathrm{M}$ IPH in the presence of different concentrations of interferents. The results of effects of interferents on the peak current of IPH are shown in Table 2.

It was noticed that the ascorbic acid did not interfere with the peak current of IPH up to 12-fold excess while the acacia powder, talc, and starch showed no effect on the peak current up to 20 -fold excess. Further, glucose and sucrose did not exhibit any interference up to 32 -fold excess. These results indicated that the proposed method is selective for the determination of IPH. Hence, IPH could be easily determined in the presence of above interferents. 
TABLE 2: Effects of interferents in the determination of $2.5 \mu \mathrm{M} \mathrm{IPH}$ at MWCNT-GCE.

\begin{tabular}{lcccc}
\hline Interferent & $\begin{array}{c}\text { Concentration } \\
{[\mu \mathrm{M}]}\end{array}$ & $\begin{array}{c}\text { Current } \\
{[\mu \mathrm{A}]}\end{array}$ & $\begin{array}{c}\text { Signal } \\
\text { change }[\mu \mathrm{A}]\end{array}$ & $\begin{array}{c}\text { RSD } \\
{[\%]}\end{array}$ \\
\hline IPH only & 2.5 & 3.510 & - & - \\
Ascorbic acid & 30 & 3.650 & 0.140 & 2.41 \\
Glucose & 80 & 3.518 & 0.008 & 1.63 \\
Sucrose & 80 & 3.520 & 0.010 & 1.55 \\
Talc & 50 & 3.525 & 0.015 & 1.68 \\
Acacia powder & 50 & 3.586 & 0.076 & 1.87 \\
Starch & 50 & 3.621 & 0.111 & 2.05 \\
\hline
\end{tabular}

TABLE 3: Results of analysis of IPH in spiked urine and serum samples at MWCNT-GCE.

\begin{tabular}{lcccc}
\hline \multicolumn{5}{c}{ Urine samples } \\
\hline IPH added $[\mu \mathrm{M}]$ & $n$ & $\begin{array}{c}\text { Amount found } \\
{[\mu \mathrm{M}]}\end{array}$ & $\begin{array}{c}\text { Average } \\
\text { recovery }[\%]\end{array}$ & $\begin{array}{c}\text { RSD } \\
{[\%]}\end{array}$ \\
\hline 2 & 4 & 1.99 & 99.37 & 1.51 \\
10 & 4 & 9.95 & 99.46 & 0.92 \\
25 & 4 & 25.02 & 100.07 & 0.23 \\
35 & 4 & 34.99 & 99.98 & 0.16 \\
\hline \multicolumn{5}{c}{ Serum samples } \\
10 & 4 & 1.93 & 96.4 & 2.20 \\
25 & 4 & 9.73 & 97.3 & 1.29 \\
35 & 4 & 24.28 & 97.1 & 1.98 \\
\hline
\end{tabular}

4.3. Determination of IPH in Urine and Plasma Samples. The practical analytical application of the method was further established by determining IPH in human urine samples without any preliminary treatment. The recoveries from urine samples were examined by spiking drug free urine with known amounts of IPH and by recording the differential pulse voltammograms. The calibration graph was used to determine the concentration of IPH in urine samples. The results of analysis are listed in Table 3 . Higher average recovery (99.37-100.07\%) and lower RSD values (less than 1.51\%) highlighted good recovery and reproducibility of the results.

The applicability of the proposed method was also examined by analyzing IPH in plasma samples. Suitable amounts of IPH spiked serum samples were diluted with supporting electrolyte and differential pulse voltammograms were recorded. The amount of IPH in serum samples was then determined by referring to the calibration plot. The results incorporated in Table 3 indicated good recovery of IPH. The proposed method is simple, easy to perform, and sensitive enough for the assay of IPH in human serum samples.

\section{Conclusions}

Multiwalled carbon-nanotube-modified glassy carbon electrode was developed as an electrochemical sensor for the assay of IPH based on the enhanced peak current responses of oxidation of IPH. This novel sensing system for IPH was found to be convenient and showed excellent analytical characteristics such as significant lowering of the detection limit, higher sensitivity, and better selectivity. The method provides a simple approach for the determination of IPH in spiked human urine and serum samples without any pretreatment. The principal advantage of the proposed method is its freedom from the interference by excipients.

\section{Acknowledgments}

The authors are grateful to the University Grants Commission, New Delhi, India, for financial assistance (F. no. 34/374/ 2008 (SR) dated 30-12-2008). Thanks are also due to the authorities of the Karnatak University, Dharwad, India, for providing the necessary facilities.

\section{References}

[1] S. Iijima, "Helical microtubules of graphitic carbon," Nature, vol. 354 , no. 6348 , pp. 56-58, 1991.

[2] P. M. Ajayan, "Nanotubes from carbon," Chemical Reviews, vol. 99, no. 7, pp. 1787-1799, 1999.

[3] J. Wang, "Carbon-nanotube based electrochemical biosensors: a review," Electroanalysis, vol. 17, no. 1, pp. 7-14, 2005.

[4] J. H. Rouse and P. T. Lillehei, "Electrostatic assembly of polymer/single walled carbon nanotube multilayer films," Nano Letters, vol. 3, no. 1, pp. 59-62, 2003.

[5] R. H. Baughman, A. A. Zakhidov, and W. A. De Heer, "Carbon nanotubes - the route toward applications," Science, vol. 297, no. 5582, pp. 787-792, 2002.

[6] J. Huang, J. Li, Y. Yang et al., "Development of an amperometric l-lactate biosensor based on l-lactate oxidase immobilized through silica sol-gel film on multi-walled carbon nanotubes/ platinum nanoparticle modified glassy carbon electrode," $\mathrm{Ma}$ terials Science and Engineering C, vol. 28, no. 7, pp. 1070-1075, 2008.

[7] K. J. Huang, D. F. Luo, W. Z. Xie, and Y. S. Yu, "Sensitive voltammetric determination of tyrosine using multi-walled carbon nanotubes/4-aminobenzeresulfonic acid film-coated glassy carbon electrode," Colloids and Surfaces B, vol. 61, no. 2, pp. 176-181, 2008.

[8] P. J. Britto, K. S. V. Santhanam, A. Rubio, J. A. Alonso, and P. M. Ajayan, "Improved charge transfer at carbon nanotube electrodes," Advanced Materials, vol. 11, no. 2, pp. 154-157, 1999.

[9] J. Wang, M. Musameh, and Y. Lin, "Solubilization of carbon nanotubes by Nafion toward the preparation of amperometric biosensors," Journal of the American Chemical Society, vol. 125, no. 9, pp. 2408-2409, 2003.

[10] K. Wu, X. Ji, J. Fei, and S. Hu, "The fabrication of a carbon nanotube film on a glassy carbon electrode and its application to determining thyroxine," Nanotechnology, vol. 15, no. 3, pp. 287-291, 2004.

[11] S. M. T. Shaikh, J. Seetharamappa, P. B. Kandagal, and S. Ashoka, "Binding of the bioactive component isothipendyl hydrochloride with bovine serum albumin," Journal of Molecular Structure, vol. 786, no. 1, pp. 46-52, 2006.

[12] H. Hattori, T. Yamada, and O. Suzuki, "Gas chromatography with surface ionization detection in forensic analysis," Journal of Chromatography A, vol. 674, no. 1-2, pp. 15-23, 1994.

[13] H. Hattori, S. Yamamoto, M. Iwata, E. Takashima, T. Yamada, and O. Suzuki, "Sensitive determination of phenothiazines in 
body fluids by gas chromatography with surface ionization detection," Journal of Chromatography, vol. 579, no. 2, pp. 247252, 1992.

[14] C. S. P. Sastry, A. S. R. Prasad Tipirneni, and M. V. Suryanarayana, "Spectrophotometric determination of some antiallergic agents with 3-methyl-2-benzothiazolinone hydrazone," Journal of Pharmaceutical and Biomedical Analysis, vol. 8, no. 3, pp. 287-292, 1990.

[15] B. Baalbaki, E. Cheble, G. Nguema, and H. Fabre, "Stabilityindicating assay using capillary zone electrophoresis for an azaphenothiazine in an ointment formulation," Analytica Chimica Acta, vol. 533, no. 2, pp. 121-125, 2005.

[16] M. Guo, J. Chen, L. Nie, and S. Yao, "Electrostatic assembly of calf thymus DNA on multi-walled carbon nanotube modified gold electrode and its interaction with chlorpromazine hydrochloride," Electrochimica Acta, vol. 49, no. 16, pp. 26372643, 2004.

[17] P. Daneshgar, P. Norouzi, M. R. Ganjali, A. OrdikhaniSeyedlar, and H. Eshraghi, "A dysprosium nanowire modified carbon paste electrode for determination of levodopa using fast Fourier transformation square-wave voltammetry method," Colloids and Surfaces B, vol. 68, no. 1, pp. 27-32, 2009.

[18] Y. H. Pai, H. F. Huang, Y. C. Chang, C. C. Chou, and F. S. Shieu, "Electron-beam reduction method for preparing electrocatalytic particles for membrane electrode assemblies (MEA)," Journal of Power Sources, vol. 159, no. 2, pp. 878-884, 2006.

[19] Y. Ni, L. Wang, and S. Kokot, "Voltammetric determination of chlorpromazine hydrochloride and promethazine hydrochloride with the use of multivariate calibration," Analytica Chimica Acta, vol. 439, no. 1, pp. 159-168, 2001.

[20] L. Huang, L. Bu, F. Zhao, and B. Zeng, "Voltammetric behavior of ethopropazine and the influence of sodium dodecylsutfate on its accumulation on gold electrodes," Journal of Solid State Electrochemistry, vol. 8, no. 12, pp. 976-981, 2004.

[21] C. Quiñones-Torrelo, S. Sagrado, R. M. Villanueva-Camañas, and M. J. Medina-Hernández, "Retention pharmacokinetic and pharmacodynamic parameter relationships of antihistamine drugs using biopartitioning micellar chromatography," Journal of Chromatography B, vol. 761, no. 1, pp. 13-26, 2001.

[22] R. I. Baxter, G. Svehla, B. Kerr, and A. D. Woolfson, "Determination of promethazine by anodic differential-pulse voltammetry," Analytica Chimica Acta, vol. 164, pp. 171-180, 1984.

[23] P. H. Sackett, J. S. Mayausky, T. Smith, S. Kalus, and R. L. McCreery, "Side-chain effects on phenothiazine cation radical reactions," Journal of Medicinal Chemistry, vol. 24, no. 11, pp. 1342-1347, 1981.

[24] A. J. Bard and L. R. Faulkner, Electrochemical Methods Fundamentals and Applications, Wiley, New York, NY, USA, 1980.

[25] D. K. Gosser, Cyclic Voltammetry: Simulation and Analysis of Reaction Mechanisms, Wiley-VCH, New York, NY, USA, 1993.

[26] E. Laviron, L. Roullier, and C. Degrand, "A multilayer model for the study of space distributed redox modified electrodespart II. Theory and application of linear potential sweep voltammetry for a simple reaction," Journal of Electroanalytical Chemistry, vol. 112, no. 1, pp. 11-23, 1980.

[27] C. M. Riley and T. W. Rosanske, Development and Validation of Analytical Methods, Elsevier Science Ltd., New York, NY, USA, 1996.

[28] M. E. Swartz and I. S. Krull, Analytical Method Development and Validation, Marcel Dekker, New York, ny, USA, 1997. 


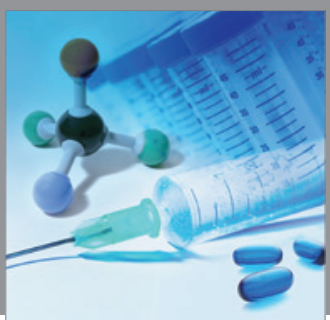

International Journal of

Medicinal Chemistry

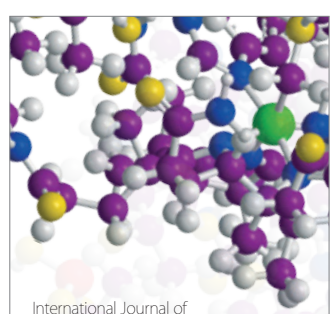

Carbohydrate Chemistry

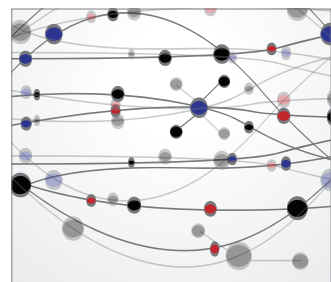

The Scientific World Journal
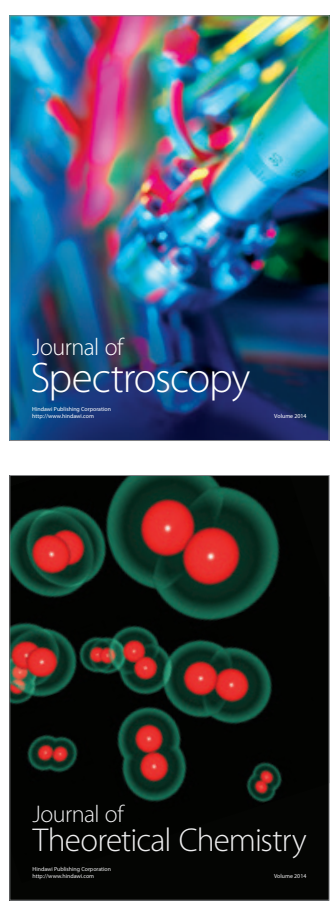
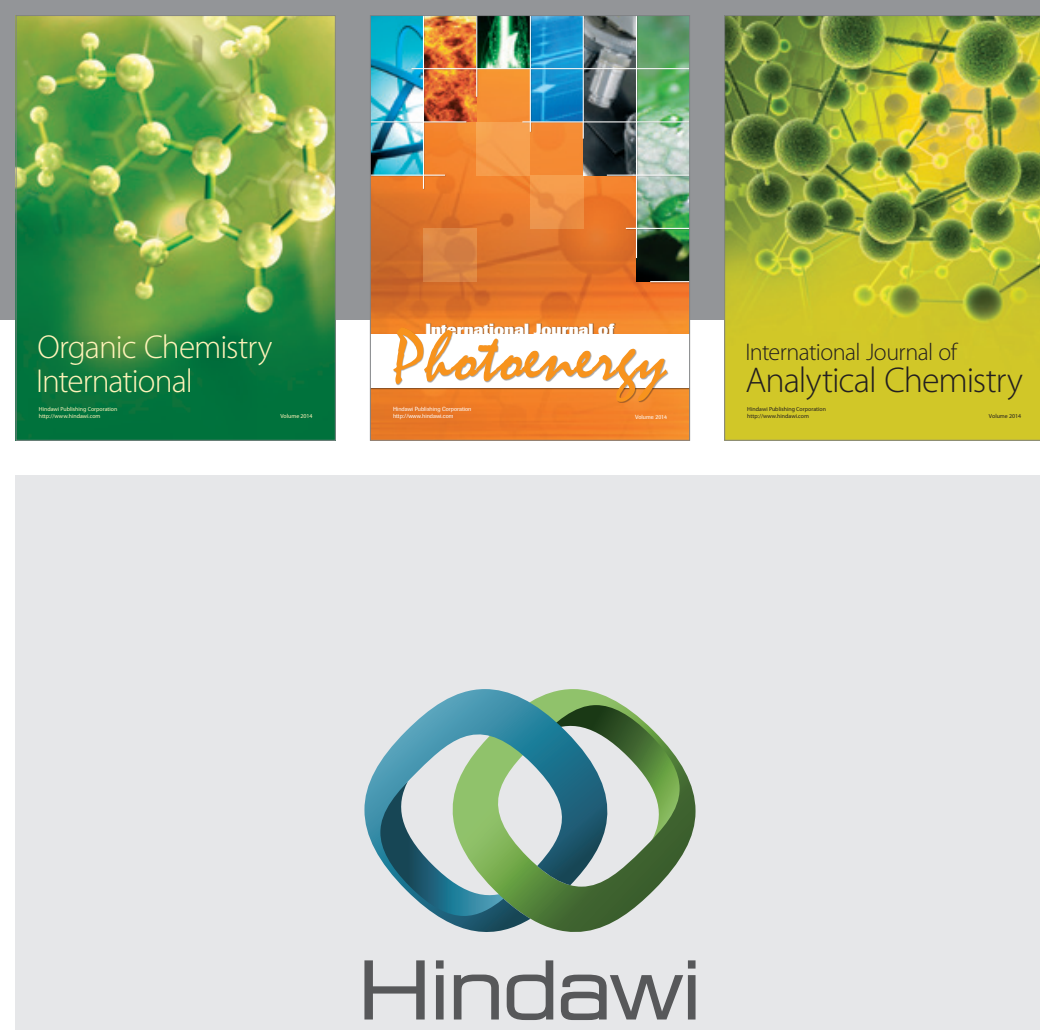

Submit your manuscripts at

http://www.hindawi.com
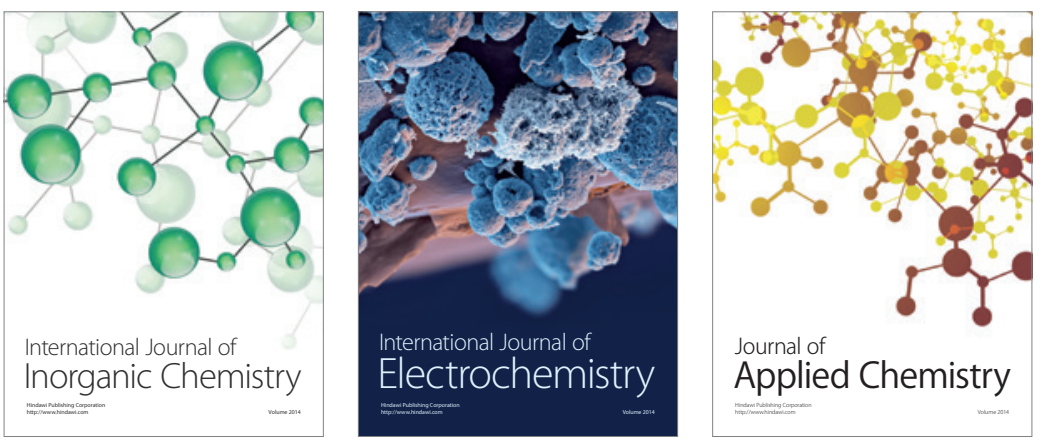

Journal of

Applied Chemistry
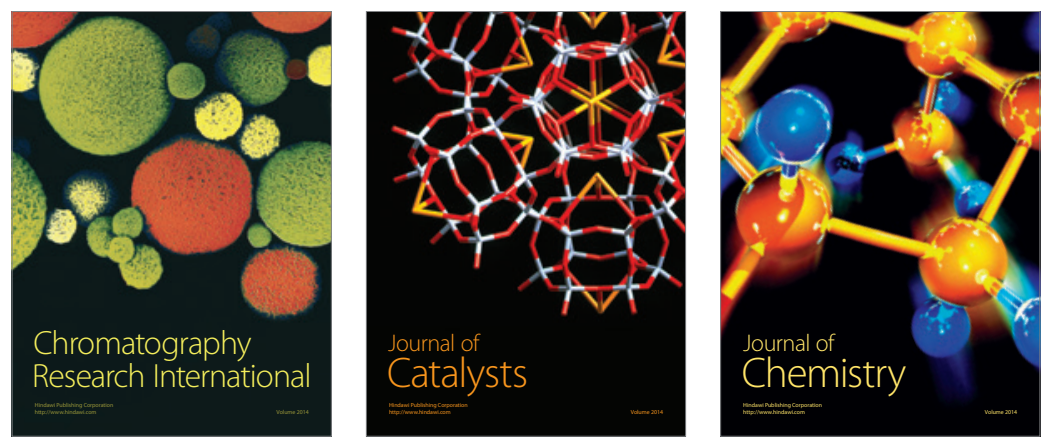
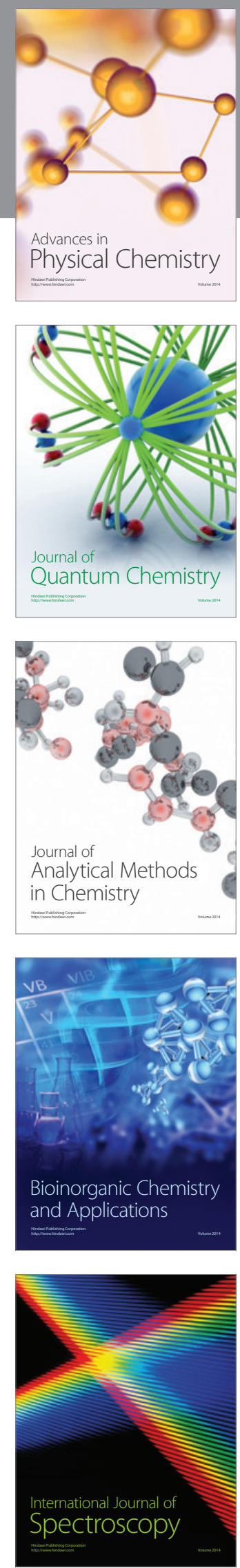